\title{
Usage of Inrush Current Surge for Early Detection of Inter-Winding Faults
}

\author{
Aleksandrs Dolgicers, Jevgenijs Kozadajevs, Ivars Zalitis \\ Riga Technical University \\ Faculty of Power and Electrical Engineering \\ Riga, Latvia \\ dolgicers@eef.rtu.lv,kozadajevs@eef.rtu.lv, zalitis@eef.rtu.lv
}

\begin{abstract}
This paper presents the development of microprocessor based device for improving the sensitivity of differential protection of power transformers. Power transformers failure may lead to high scale system's operations disruption and heavy economic losses, that's why the lever of requirements for power transformer protections is so high. Differential protection is usually used as a main protection against internal faults such as inter-windings faults, inter-coil faults or coil-core faults. For safe protection against incomplete winding faults protection device must be capable to detect differential current from such a very low value from nominal. The idea for a new device is to use information extracted from inrush current thru Fourier transformation to perform an early detection of faults usually hardly detectable due to very low impact on transformer's primary current in steady condition. In case of fault device may operate with much higher sensitivity thus sensing fault on its early stage.
\end{abstract}

Keywords- differential protection of power transformers, sensitivity of relay protection, internal faults, inrush current.

\section{INTRODUCTION}

Power transformers are highly valued power system's elements, transformers failure may lead to high scale system's operations disruption and heavy economic losses. Transformer damages are often linked with long term customer disconnections or available power limitations. That's why the lever of requirements for power transformer protections is so high. Between transformer damages internal and external damages are distinguished. Under the term "internal damage" are understood any kind of damage, that is located inside the transformer's shell or tank. Internal damage may cause winding destruction, fire and transformer's blow-up, which leads to complete transformer destruction. Protection against internal faults is a matter of high importance. Differential protection is usually used as a main protection against internal faults such as inter-windings faults, inter-coil faults or coil-core faults. [1].To understand the basics of such protection let's discuss the simplified schematics on the Fig. 1.

The current transformer TA1 is inserted into the primary windings circuit of the protected power transformer, another current transformer TA2 is used to monitor current in the secondary winding's circuit. Both current transformers are selected in such way, that in case of nominal load of protected transformer they secondary currents are equal. Fig 1.a shows circuit operation in cases of normal load or external damage. The current relay KA is fed by difference of currents from TA1 and TA2, in case of external fault or load this currents are equal by amplitude and opposite by direction, so resulting current in the KA coil is equal to zero and no output is produced. Complete opposite situation is observable in case of internal fault. Both currents are directed toward fault and as shown on Fig 1.b, KA will receive near double fault current and with KA trip the disconnection signal for power switches will be produced. Reader may come to conclusion, that protection device, based on differential principle will be absolutely selective and will benefit an unlimited sensitivity. In the real world protection sensitivity is limited by the number of factors, partially linked with protected transformer, such as magnetizing current, (especially rapid changes in it) or change of real transformation ratio occurring when the voltage regulator changes the taps during it's operation and partially inflicted by the current transformers errors.
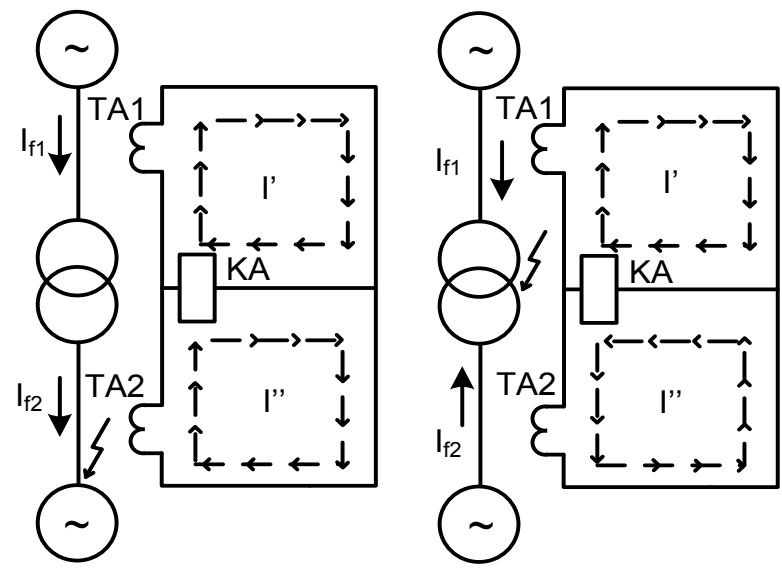

Fig.1 Basic principle of differential protection's operations

Let's designate the current in the KA under normal regime conditions or in case of external fault as unbalance current. In the ideal case the unbalance current $I_{n b}=0$, the real value of this current is damaged leg of transformer may be represented by schematic shown on Fig. 3. To simplify equations let's consider, that before the fault (internal) transformer didn't carry any load. 


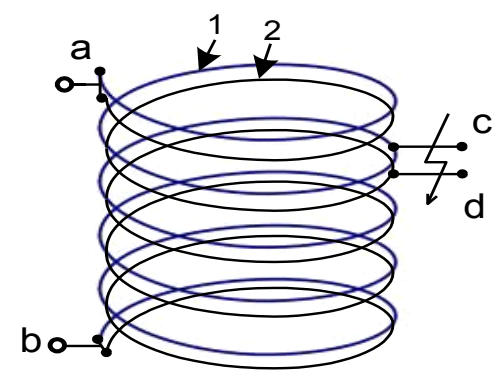

a)

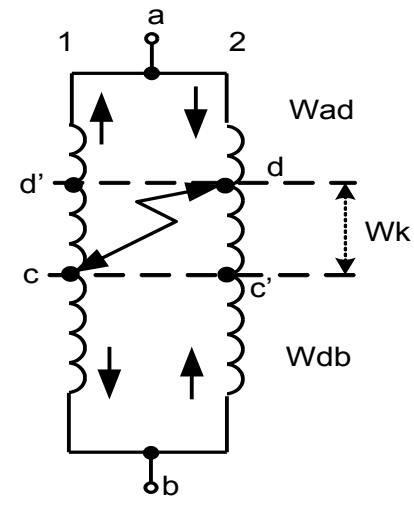

b)

Fig. 2 Transformer's winding formed by two parallel wires

Two opposite EDF $E_{K}$ and $E_{K}{ }^{\prime}$ are inserted between points of fault $c$ and $d$ both equal to multiplication of single wind voltage $U_{w}$ by number of faulted winds $W_{k}$, power network is represented by the EDF $E_{n}$ behind resistance $Z_{N}$. Let's use superposition method [4] representing real regime as combination of two partial regimes, in our case prefault and fault. Schematic, representing the fault regime is shown on the Fig.4.

\section{ESTIMATION OF REQUIRED PROTECTIONS SENSITIVITY}

Let's find an estimation of required protections sensitivity. The hardest task for the differential protection is opening of so called incomplete winding faults, which may occur in the multi- wire transformer windings, when a coil is formed from multiple parallel wires ( such design is preferable for high current transformer coils for technology reasons) [1] Let's discuss transformer's winding made of two parallel wires (Fig 2.a) with common terminals $a$ and $b$. Any insulation damage will cause short circuiting between windings of different parallel branches (points $c$ and $d$ ) and, in common case, between different winding (at last one winding shift will occur). Faults current is limited by resistance of two contour's $c a d$ and $c b d$ (see Fig 2.b) formed by parallel winded wires and may be estimated by the method proposed by L. Leites considering the short-circuited part of common winding as a separate [3].

Let's introduce parameter

$$
\alpha=\frac{w_{a d}+\frac{1}{2} w_{k}}{w_{a d}+w_{k}+w_{c b}},
$$

Current in the place of fault may be found as

$$
I_{k}=\frac{U_{k}}{Z_{e}+\alpha(1-\alpha) 2 m \cdot R_{a b}}
$$

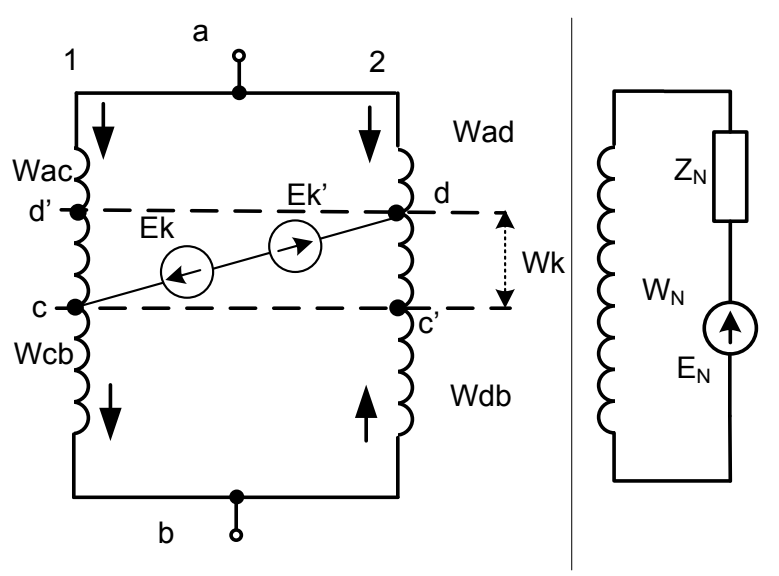

Fig. 3 Equivalent schematic of one transformer's leg

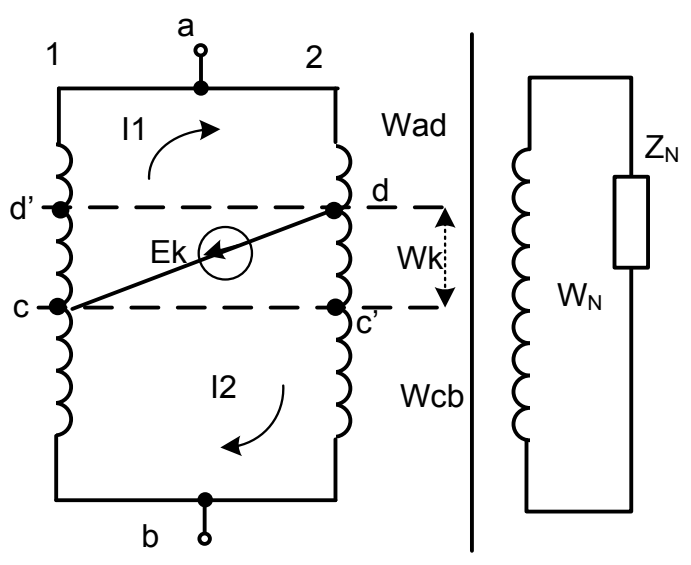

Fig. 4 Fault regime of transformers coil

The topmost value of $I_{\kappa}$ corresponds to

$$
\alpha_{\max }=\frac{w_{k}}{2\left(w_{a d}+w_{k}+w_{c b}\right)}
$$


and $\left(1-\alpha_{\max }\right)$, smallest value is $\alpha_{\min }=\frac{1}{2}$, i.e. fault is in the middle of the winding. The fault component $I_{N}$, which determines operation of differential protection may be found as

$$
I_{N}=\frac{I_{k} \cdot W_{k}}{W_{N}}
$$

According to the works of Alexander Zasypkin calculus of $I_{N}$ currents for transformers produced by ZTZ factory with rated power from 25 to $1000 \mathrm{MBA}$ yielded $I_{N}$ in range from $6 \%$ to $30 \%$ of transformer's nominal current. For the small transformer we use in our laboratory for testing primary current increase in case of simulated one turn fault was only $2.85 \%$. Meanwhile the fault current is not less than $(\alpha+(1-\alpha)) \cdot I_{n o m}$ and poses a real danger for transformer. Thus for safe protection against incomplete winding faults protection device must be capable to detect differential current from such a low value as 0.01 from nominal, that is far below unbalance current of ordinary current transformer. Must be mentioned, that failing to detect incomplete winding fault timely will lead to inter-coil insulation burn-off and transition from incomplete winding fault to the full coil fault between coil levels or coil - coil fault with typical $\mathrm{I}_{\mathrm{N}}$ varying from $10 \%$ to $150 \%$ of nominal current.

\section{INRUSH CURRENT OF TRANSFORMER WITH STEEL CORE}

To understand idea of proposed improvement lets discuss inrush current of single phase transformer with saturable core made of steel. For transformer just connected to the network primary voltage may be written as

$$
u_{1}(t)=U_{1 m} \sin (\omega t+\psi)
$$

where $\psi$ denotes angle at a time of connection. On the basis of classical transients theory we may assume, that core flux may be represented as sum of two components - one corresponding to so called forced regime, mean regime for infinite time. This flux can be determined from equilibrium based on assumption, that self-induced electric force of primary winding linked with this flux is equal to the primary voltage $u_{1}(t)$. So forced flux will be a time function in form

$$
\Phi_{\infty}(t)=\Phi_{m} \sin (\omega t+\psi-\varphi)
$$

where $\Phi_{m}=\frac{L_{1} U_{1 m}}{w_{1} \sqrt{R_{1}^{2}+\omega^{2} L_{1}^{2}}} ; R_{1}$ denotes summary active resistance of primary winding, $L_{1}$ denotes primary winding inductance and angle $\varphi=\operatorname{arctg} \frac{\omega L_{1}}{R_{1}}$, for any transformer excluding very small $\varphi \approx \frac{\pi}{2}$, so we can write $\Phi_{\infty}$ as $\Phi_{\infty}(t)=\Phi_{m} \cos (\omega t+\psi)$. As another component of the flux we can assume so called free or independent component $\Phi_{\tau}(t)$. Transients theory usually seeks solution to differential equation in form of $f(t)=A e^{-\alpha t}$ so in our case reasonable form for free component of flux will be

$$
\Phi_{\tau}(t)=\Phi_{m} \cos \psi \cdot e^{-\frac{R_{1}}{L_{1}} t}
$$

where $\Phi_{m} \cos \psi$ gives us flux for commutation moment $\mathrm{t}=0$. But there is one serious drawback, real transformers core may have some residual magnetisation and thus some residual flux $\Phi_{r}$. It is hardly to predict direction for $\Phi_{r}$ so it may have positive or negative direction at the time transformer is connected to the network. Taking into account $\Phi_{r}$ free flux will become

$$
\Phi_{\tau}(t)=\left(\Phi_{m} \cos \psi \pm \Phi_{r}\right) \cdot e^{-\frac{R_{1}}{L_{1}} t}
$$

The easiest possible transient will occur in case than residual flux $\Phi_{r}=0$ and $\psi=\frac{\pi}{2}$ In such case

$$
\begin{aligned}
& \Phi(t)=\Phi_{\infty}(t)+\Phi_{\tau}(t)= \\
& -\Phi_{m} \cos \left(\omega t+\frac{\pi}{2}\right)=\Phi_{m} \sin (\omega t)
\end{aligned}
$$

meaning no transient at all. The heavier one will occur if $\psi$ is equal to 0 or $\pi$ and residual flux $\Phi_{r}$ is directed against $\Phi_{\infty}$. In such case flux

$$
\Phi(\mathrm{t})=-\Phi_{m} \cos (\omega t)+\left(\Phi_{m}+\Phi_{r}\right) * e^{-\frac{R_{1}}{L_{1}} t}
$$

and will achieve its maximum in time approximately one half period after transformer being energised, $t \approx \pi$. For most transformers $R_{1}<<\omega$ and $e^{-\frac{R_{1}}{L_{1}} t}$ will become approximately equal to 1 . At this point flux $\Phi(t)$ will achieve its maximal magnitude, somewhere about $2 \Phi_{m}+\Phi_{r}$, that mean very deep saturation of transformer core and definitely will cause serious surge of inrush current. In real life transformers inrush transient process will be somewhere between easiest and heaviest one. To illustrate inrush current formation we use chart where line in the 1-st quadrant represents transformers core magnetising line $\Phi=f\left(I_{1}\right)$, line in the second quadrant is our flux $\Phi(t)$ drawn on the inverted time axis and current is constructed in the 4-th quadrant using down directed time axis (see Fig.5).

\section{INRUSH CURRENT OF TRANSFORMER WITH SHORTENED TURNS}

Let's now discuss situation, when our transformer has one or more short-circuited turns. Faulty part of the winding will become a some form of separated winding with $w_{k}$ turns in it. Induced $E_{k}(t)$ will be

$$
E_{k}(t)=-w_{k} \frac{d \Phi(t)}{d t}
$$

In whole flux $\Phi(\mathrm{t})$ part $\Phi_{\tau}(t)$ changes in time much slower, than $\Phi_{\infty}(t)$ so $E_{k}(t)$ will be mostly determined by $\Phi_{\tau}(t)$. Since turns $w_{k}$ are shortened current will flow and flux 


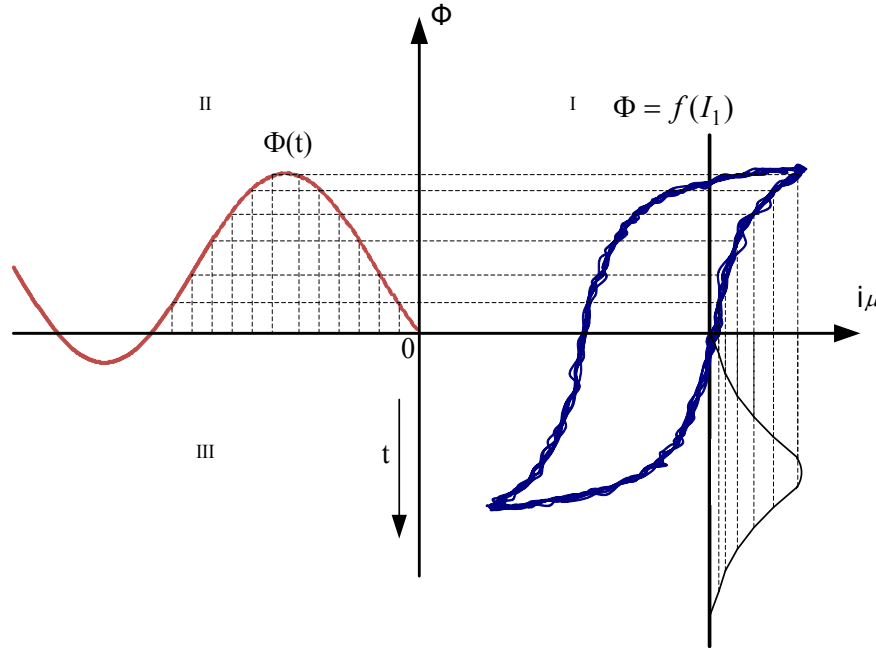

Fig.5 Formation of inrush current
$\Phi_{k}(t)$ will arrive. Important thing about this flux is that it will be directed against $\Phi_{\tau}(t)$ actually reducing saturation degree of transformers core. To illustrate this phenomena recorded magnetisation loops of our test transformer are presented ( see Fig. 6).

We have recorded magnetisation loops of healthy transformer and transformer with artificially created short circuited turn. As reader may see, changes in primary current are quite small, especially if we take into account, that most protective relays will use effective value or perform a form of discrete Fourier transformation to extract orthogonal values of first harmonics. Meanwhile changes on the "horns" of loop are quite significant and is absolutely clear, that saturation degree is quite lower. Figure 7 shows how $\Phi_{k}(t)$ presence impacts inrush current. Recordings on Fig. 8 show inrush current of healthy test transformer a) and transformer with two turn shortened (b). As predicted, current on second recording contains less higher harmonics, than in case of healthy transformer.

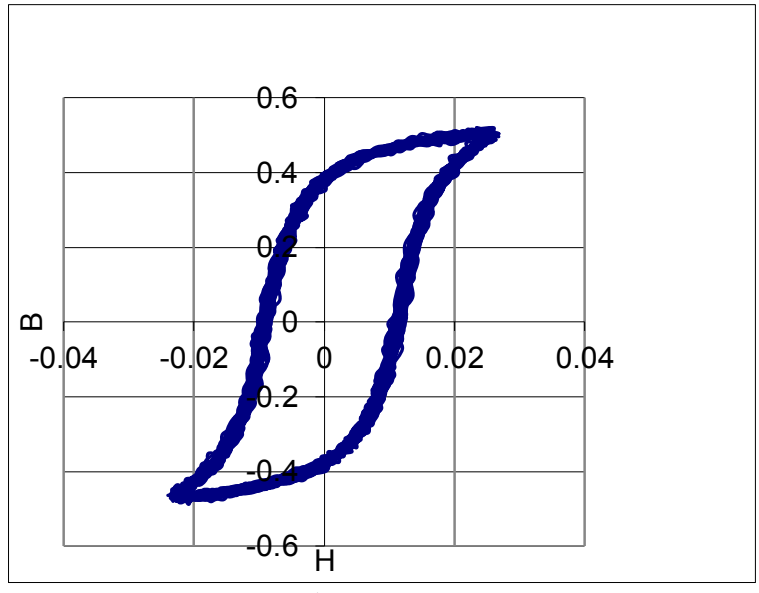

a)

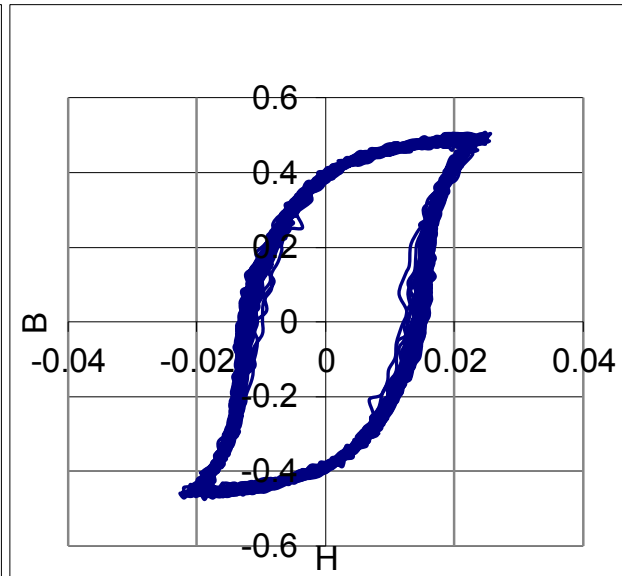

b)

Fig.6 Magnetisation loops of test transformer, a) - good condition, no shortened turns, b) short-circuit of one turn.

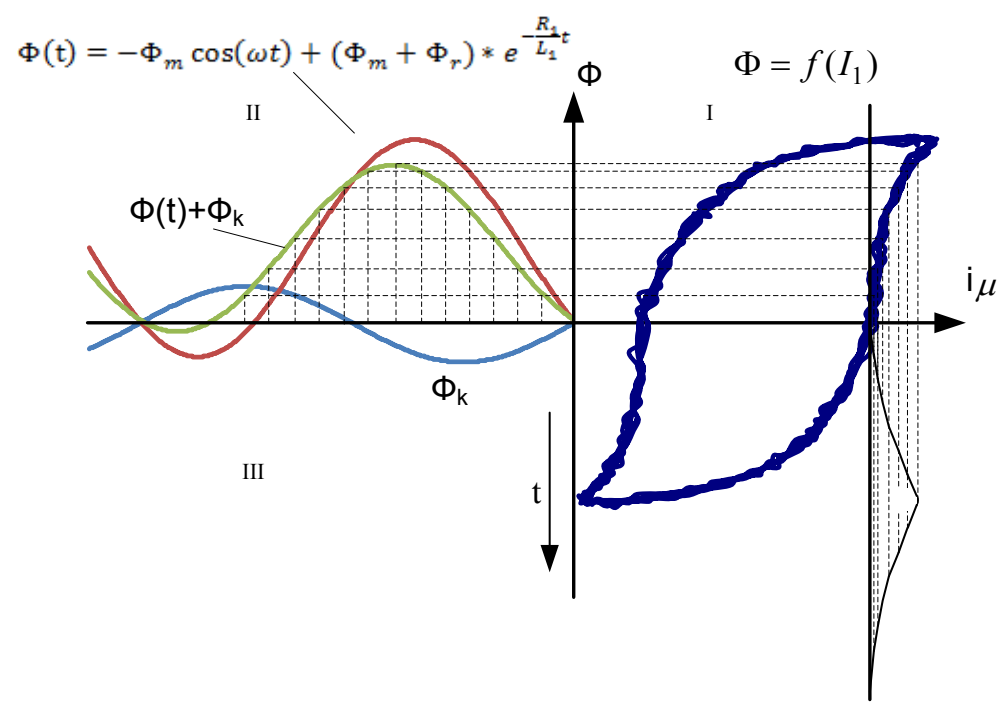

Fig. 7 Transient current in case of shortened turns presence. 


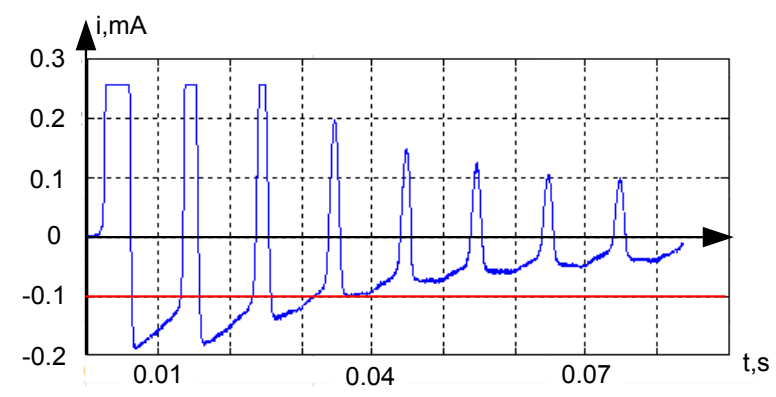

a)

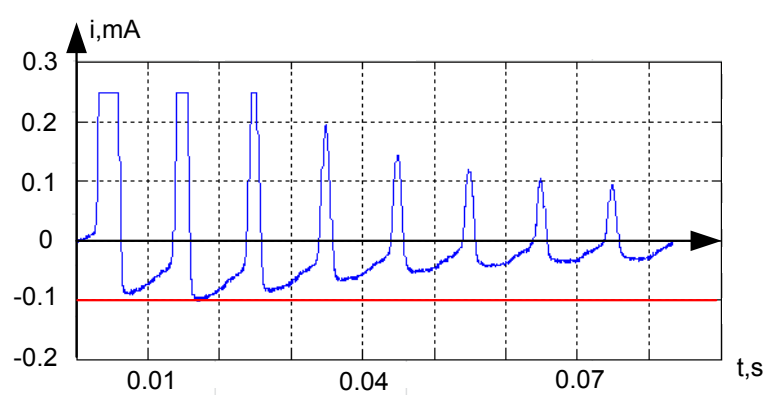

b)

Fig. 8 Recordings of inrush current of healthy transformer a) and with two turn shortened b)

\section{USAGE OF INRUSH CURRENT DEFORMATION PHENOMENA FOR EARLY DETECTION OF INTER-WINDING FAULTS}

As we can conclude, current of energized transformer changes significantly in case of inter-winding fault presence and simple relay, based on some form of discrete Fourier transform, will successfully distinguish inter-winding faults on the early stage of fault. But problem is more complicated, that it may appear. Real transient process depends heavily from commutation angle $\psi$ and residual flux $\Phi_{r}$. Of course the best solution to this problem is to equip protective device with a model of transformers magnetic system and compare real transient current with calculated by the model using voltage measurements at point of commutation. Angle $\psi$ can be easily determined from voltage channel record. Flux $\Phi_{r}$ also can be determined from recording of previous disconnection of transformer from network or thru the way of integration of secondary voltage and extraction of exponential component . But full scale model may appear too complicated for microprocessor device with reasonable price, so as a budget solution we do propose a less sensitive but more affordable approach. At present time we do have in our dispose quite good line differential protection terminal LIDA [11], so we are aiming to transform it into transformer protection terminal with winding fault detection function. The idea of detection algorithm, targeted for LIDA, is first to clear recorded inrush current ( device should first record some $100-200$ milliseconds of transient and then perform analysis hoping, that transformer can survive some $500 \mathrm{~ms}$ of fault regime) from noises and exponential component, than cut off half waves corresponding to higher peaks ( this part corresponds to regions, where $\left.\operatorname{sign}\left(\Phi_{\tau}(t)\right)=\operatorname{sign}\left(\Phi_{\infty}(t)\right) \quad\right)$ and then perform a discrete Fourier transformation of remained signal. Such approach is more promising in the aspect of sensitivity, than one used in [11] because Fourier transformation's subject if freed from sharp changes less depended from winding state, but giving large presence of high harmonics.

As a trip condition derived function for higher harmonics (at least from $7^{\text {th }}$ to $15^{\text {th }}$ ) complex amplitude must be used. We tested this approach on some dozens inrushes, both from controlled voltage source and power network. Should be mentioned, that at present time we used preliminary demagnetised core, thus ensuring known $\Phi_{r}$. So, here are testing results see TABLE 1 , undamaged transformer at the left side and transformer with two short-circuited turns at the right side.

TABLE I. INRUSH CURRENT HARMONIX AMPLITUDE

\begin{tabular}{|c|c|c|c|}
\hline $\begin{array}{c}\text { Harmonics } \\
\text { Nr. }\end{array}$ & $\begin{array}{c}\text { Average } \\
\text { amplitude } \\
\text { (healthy } \\
\text { transformer), } \\
\mathbf{A}\end{array}$ & $\begin{array}{c}\text { Average } \\
\text { amplitude } \\
\text { (damager } \\
\text { transformer), } \\
\mathbf{A}\end{array}$ & $\begin{array}{c}\text { Amplitude difference } \\
\text { (healthy/ damaged), } \\
\text { \% }\end{array}$ \\
\hline 1 & 1 & 1 & 0.00 \\
\hline 2 & 0.4588 & 0.4661 & 1.60 \\
\hline 3 & 0.0569 & 0.0416 & 26.88 \\
\hline 4 & 0.2608 & 0.2436 & 6.60 \\
\hline 5 & 0.1548 & 0.1466 & 5.32 \\
\hline 6 & 0.0814 & 0.0685 & 15.76 \\
\hline 7 & 0.1436 & 0.1320 & 8.06 \\
\hline 8 & 0.1470 & 0.2163 & 47.10 \\
\hline 9 & 0.3600 & 0.4382 & 21.73 \\
\hline 10 & 0.4784 & 0.5158 & 7.81 \\
\hline 11 & 0.3705 & 0.3655 & 1.35 \\
\hline 12 & 0.1251 & 0.0876 & 30.03 \\
\hline 13 & 0.1103 & 0.1352 & 22.53 \\
\hline 14 & 0.1514 & 0.1518 & 0.25 \\
\hline 15 & 0.0724 & 0.0613 & 15.34 \\
\hline & & & \\
\hline
\end{tabular}

Values are normalized towards fundamental harmonic and, as reader can see, changes between healthy and damaged transformer are quite significant promising highly sensitive protection.

\section{CONCLUSIONS}

The picture of upper harmonics of inrush current changes significantly in case of inter-windings fault presence, so such fault may be detected on its' early occurrence using information, extracted from inrush regime, and a good improvement of transformer protective device can be made, meanwhile maintaining good robustness level in case of other types of fault. 


\section{REFERENCES:}

[1] The Iinstitution of Engineering and technology. Power sysyems protection Volume 3 . Lighting Source UK, Milton Keynes 2007.

[2] A.Voldek, ,Elektricheskie mashiny” [Electric machines]. 1978, p 832.

[3] L. Leites "Elektromagnitnie rascheti transformatorov toka." — Moscow, Energy, 1981, p 392.

[4] G. Atabekov „Osnovi teoriy cepey”, Lany, 2009.

[5] A. Zasypkin. 'Relejnaja zashita "' 1989.

[6] ABB Instrument transformer application guide, ABB 2011.
[7] A. Drozdov „Elektricheskie cepi s ferromagnitnimi serdechnikami d relejnoj zashite". Energy, 1965.

[8] Berkovich "Spravochnik po relejnoj zashite" 1972.

[9] [9.] A. Sauhats, A.Vasiljjevs, S.Leščenkovs, „Transformatoru aizsardzība un automātika", Rīga 2003, p 17.

[10] [10] Mārtiņš Silarājs, Andrejs Utāns, Lilija Leite, Antans Sauhats. Multifunctional relay protection device for power transmission lines LIDA. Electrical and control technologies. Proceedings of the 2nd international conference. Kaunas EST 2007. ISSN 1822-5934. p. 120125.

[11] Kulidjian,et al United States Patent 6,483,680. 2002

This is a post-print of a paper published in "Proceedings of the 2014 15th International Scientific Conference on Electric Power Engineering (EPE)" [http://dx.doi.org/10.1109/EPE.2014.6839528] and is subject to IEEE copyright. 